\title{
Why Isn't Our Chat Reference Used More?
}

\section{Finding of Focus Group Discussions with Undergraduate Students}

\author{
Sharon Naylor, Bruce Stoffel, \\ and Sharon Van Der Laan
}

\begin{abstract}
Sharon Naylor is Education Librarian and Associate Professor at Milner Library, Illinois State University, Normal. Bruce Stoffel is Reference Coordinator and Assistant Professor at Milner Library, Illinois State University, Normal. Sharon Van Der Laan is Communication Librarian and Instructional Assistant Professor at Milner Library, Illinois State University, Normal. Submitted for review September 18, 2006; accepted for publication December 7, 2006.
\end{abstract}

Reference \& User Services Quarterly, vol. 47, no. 4, pp. 342-354

(c) 2008 American Library Association. All rights reserved.

Permission granted to reproduce for nonprofit, educational use.
Despite early reports of patron enthusiasm with chat reference, usage of this service has been disappointing at some academic libraries, including our own. To probe why students have not used our chat reference service more, we conducted in-depth focus group discussions with upper level undergraduates on our campus. We questioned participants-all nonusers of chat reference-about their research behaviors and their reference service preferences. Responses suggest users desire both a variety of reference services and more personalized reference services. We discuss implications for how we deliver chat reference.

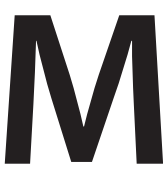
ilner Library at Illinois State University, like many other libraries, has been providing some form of chat reference for several years. We had heard and read the predictions of those who pointed to our declining reference statistics, proclaimed traditional reference obsolete, and declared chat reference services to be our salvation from extinction. We read and believed forecasters like Coffman and McGlamery who wrote that the situation necessitated "that reference librarians revolutionize their service approach if they're to stay in business." We were motivated not only by our desire to serve our users, but also by our fear of being replaced by the likes of Ask Jeeves. But now, over five years after our initial venture into a consortial chat reference project, we are left asking ourselves, "what happened?" Academic libraries slowly drifted away from our consortium, and our statistics remained modest at best. LSSI, the company whose chat reference software we initially used, now exists as something much different than it was five years ago, and Ask Jeeves and other similar services either have changed dramatically or no longer exist. Steve Coffman, a pioneer and early advocate of chat reference, when recently addressing the question of whether "to chat or not to chat" answered "it depends."

Milner Library still offers a chat reference service, although we are not currently part of a consortium. Instead of comparing software packages or asking who will take the early morning hours so we can offer 24/7 service, we have stepped back and started asking different questions-probably the questions we should have asked five years ago. How do our users conduct their research? What are their preferred ways of locating information? Does chat reference appeal to them as an avenue for asking library-related questions? Do they even understand 
what we are talking about when we use the term "chat reference"?

From everything we know about current undergraduates, often referred to as "Millennials" and characterized as technology-savvy multi-taskers wanting immediate gratification, we would expect that large numbers of them would gravitate toward chat reference. That has not been the case. Although a lack of marketing had been offered as one explanation, and we knew that was undoubtedly an issue, we suspected that other factors were also involved.

The primary intent of our study was to learn why students are not using our chat reference service, but we also wanted to determine their preferred ways of seeking information. We were interested in probing participants' use of Instant Messaging (IM) and chat, whether they use it in their daily lives, and whether they would be likely to use it to seek research assistance from librarians. Because we wanted to gain a deeper understanding of the attitudes and information-seeking behaviors of our students, we felt that a survey would not adequately reveal the type of deep attitudinal information we wanted. Instead, we chose to conduct focus groups.

The focus groups were held in Milner Library at Illinois State University, the state's first public university, founded as a normal school for teacher training in 1857 . The university serves primarily undergraduate students on a residential campus located in central Illinois. At the time of the focus groups, undergraduates numbered 17,858 of the 20,653 students enrolled. While Illinois State remains strong in its teacher education programs, the university currently offers a variety of programs. Thirty-four academic departments in six colleges offer sixty-six programs leading to the bachelor's degree, forty programs leading to the master's, and eight to the doctorate.

\section{LITERATURE REVIEW}

There have been numerous studies of patron satisfaction with chat reference. Most users surveyed in these studies indicated fairly high levels of satisfaction with chat reference. ${ }^{3}$ But the number of chat users has been disappointing for us and for librarians at other institutions. Instead of chat reference overtaking other forms of reference services, as had been predicted, some libraries have dropped their chat services.

The McGoogan Library of Medicine at the University of Nebraska decided to discontinue its virtual reference service at the end of February 2004. Librarians there determined that the number of questions received from their targeted audience, when considered in light of the cost, was too low to justify renewing the service contract. ${ }^{4}$ After conducting an extensive, four-part assessment of their library services, MIT librarians also decided to suspend their online reference service. They concluded that although the service was popular and successful with a fairly small group of users, it did not enjoy the level of popularity they had anticipated. Like the McGoogan Library, the MIT libraries determined that the usage did not justify the resources that were required. The MIT assessment included an analysis of chat reference transcripts and two user surveys: an online survey of four-hundred chat reference users (with seventy-five responses) to obtain their impressions and expectations of the chat reference service and an online and print survey of library patrons (with 993 responses) to obtain their perceptions of library services and information about their research needs and habits. ${ }^{5}$

Relatively few articles discuss attitudes or information-seeking characteristics of chat reference users. Janice Koyama speculated that users for whom being online is second nature might prefer the anonymity and freedom of the virtual environment to the experience of face-to-face encounters. ${ }^{6}$ Myoung Wilson theorized that users who avoid asking for assistance in libraries would be attracted to online options for seeking information on their own. ${ }^{7}$ But research does not necessarily support these predictions. One of the unexpected findings of the MIT study was that some people felt that chat reference would be "invasive," and some were concerned about asking "stupid questions." The MIT study also indicated that patrons already in the library overwhelmingly found face-to-face interaction the most efficient and preferred method of interaction. ${ }^{8}$

A 2002 study by Corey Johnson of Washington State University reported similar conclusions, noting that "one of the most notable trends ... is the solid popularity of in-person reference." Johnson's findings are based on 276 responses to an e-mail survey of undergraduate students, graduate students, and faculty members at two four-year public universities in the South Atlantic region. Surveys were sent to 967 people randomly selected from campus directories. The vast majority of respondents had used in-person reference, and similar numbers chose it as their first option when seeking reference assistance in a hypothetical scenario. Of particular interest in Johnson's study is that undergraduates were more likely than the graduate students or faculty to choose face-to-face reference as their first choice, yet this is the demographic group that was expected to embrace chat reference. 
Data collected by a 2002 OCLC survey seems consistent with the Johnson and MIT findings. The OCLC survey found that "if students need help when using the Web for study assignments, they prefer face-to-face interaction to online or even telephone contact. Four out of five students are more likely to seek help in-person, compared to one- in -two who ask online or by telephone."10 But it should be noted that when asked if they would use online help available from librarians at no charge, 62 percent said they definitely would. The OCLC study was conducted by Harris Interactive via the Internet. Harris sampled 1,050 U.S. college students who used the Internet for schoolrelated assignments.

A Bowling Green University study, however, had much different conclusions. In this survey, almost as many chat reference users accessed the service from within the libraries ( 29 percent) as from off campus (32 percent), although the survey did not probe deeply enough to explain why this was the case. The Bowling Green findings were based on 209 responses to an online survey that appeared to patrons at the end of their chat reference sessions. ${ }^{11}$ Similarly, some students surveyed at the University of Illinois volunteered that they did not like to ask questions in person. ${ }^{12}$ Researchers there found that 5 percent of those interviewed who used chat did not like asking questions in person. Undergraduates mentioned not liking to ask questions in person by a two-to-one margin compared to graduate students (7 percent to 3.5 percent). Although 7 percent of a selected group may not be an overwhelming number, it is still noteworthy, especially since respondents volunteered this information. It should be noted that, like the Bowling Green University survey, the University of Illinois survey was offered to users at the completion of their virtual reference sessions, so the data does not include persons who chose not to use chat reference. In the University of Illinois study, 628 chat reference patrons were sent the URL to an online survey in a standardized chat session closing message, and 345 responded.

Although the Washington State and MIT studies, which found more support for face-to-face encounters, targeted broader audiences, including both chat and non-chat users, the University of Illinois survey is more recent and might be more reflective of younger students. There is some speculation in the literature that as new students enter college, they will have increasingly sophisticated experiences and expectations. The University of Illinois survey, even though conducted only a year after the Horowitz and Johnson studies and two years after the OCLC study, may reflect changing student attitudes.
Several studies indicate that immediacy is a major reason why users choose chat reference. ${ }^{13}$ There are fewer explanations of why students are not choosing it in the numbers anticipated. Several authors discuss some of the inherent shortcomings of chat reference, but they offer no direct link connecting these shortcomings to user behaviors. One of the identified shortcomings of chat reference is the time involved, which on the surface may seem contradictory to the claim that immediacy is one of its strengths. Lee noted that a 163-word chat conversation would take more than seven minutes, but if the same conversation were spoken it would take just over one minute. ${ }^{14} \mathrm{~A}$ University of Illinois analysis of six hundred chat reference transactions logged during a twelve week pilot program also indicated that chat interviews were longer on average than transactions at the reference desk. ${ }^{15}$

The length of time involved may have been one of the considerations Lauer and McKinzie had in mind when they wrote that "Anyone who has been part of a chat room, a listserv discussion, or an Instant Messenger conversation knows the limitations of these media relative even to a telephone conversation." ${ }^{16}$ The telephone is noted in other articles. One of the steps MIT librarians took after suspending their chat reference service was to designate a single telephone line to reach general library help. ${ }^{17}$ Coffman and Arret asserted that "plain old telephone reference could have some distinct advantages over chat technologies," and pointed out that the average chat runs about fifteen minutes, or three times as long as what is often allowed on the phone. ${ }^{18}$

Another potential explanation of why some students are not using chat may lie in the nature of the communication. Although chat and IM may be popular for social interactions, it seems less clear that they are well suited for other types of communication. Lee suggested, "perhaps chat is an inherently poor technology to accomplish the communication exchange known as the reference interview."19 The Parents and Teens 2004 Survey, sponsored by the Pew Internet and American Life Project, examined teenagers' communications choices and confirmed that today's teenagers are savvy users of technology who use a variety of information technologies. The Pew researchers conducted telephone interviews with 1,100 teenagers and their parents as well as four focus groups involving a total of thirty-eight middle and high school students. Notwithstanding the popularity of electronic devices available to teenagers and their "great appetite" for new information technologies, the landline telephone remains the most dominant communication medium in their everyday lives. 
Perhaps more important for our current study, the report also notes that the mode of communication teens select varies according to the nature of the message. Despite the general preference for the telephone, there were some instances where a significant number reported that IM or e-mail would be their preferred mode of communication. "In some situations, notably for more serious conversations, teens preferred face-to-face conversations." ${ }^{20}$ Similarly, Coffman and Arret note that "when it comes to getting serious questions answered live, people seem to prefer the phone by a very wide margin," although Coffman and Arret do not provide their source. ${ }^{21}$ Perhaps our students understand the limitations of communicating using chat, IM, and e-mail and are consciously choosing other forms of communication over electronic options.

With regard to research methodology, most studies of patron attitudes toward reference services and, more specifically, toward chat reference conducted thus far have relied on surveys. Some of these studies have utilized results of brief online surveys that automatically appear on the patron's computer screen after a chat reference session. Other studies have utilized more traditional survey instruments, most typically administered using Web-based forms and e-mail to solicit patron participation. Largely lacking thus far in the professional literature is documentation of patron preferences and perspectives regarding reference services gathered through more in-depth research methods such as personal interviews or focus groups. That level of depth and meaning is what we sought to find through our research.

Fortunately, there is a considerable volume of literature in the social sciences describing focus groups as well as literature in library science describing application of the focus group interview to planning and assessing academic library services. When designing our research we relied heavily on Focus Groups: A Practical Guide for Applied Research by Richard Krueger and Mary Anne Casey. Also helpful is a 2003 article by Marilyn Von Seggern and Nancy Young entitled "The Focus Group Method in Libraries: Issues Relating to Process and Data Analysis." A more recent contribution to focus group research in libraries is "Focus Group Interviewing in the Library Literature: A Selective Annotated Bibliography 1996-2005," by Graham Walden of The Ohio State University. ${ }^{22}$

\section{CHAT REFERENCE AT MILNER LIBRARY}

In late 2000, Milner Library joined the Alliance Library System in organizing one of the first consortial chat reference services in the country. Known as Ready for Reference, the service involved eight academic libraries in central Illinois and was funded by the Illinois State Library. The Ready for Reference consortium retained LSSI to provide chat software, technical assistance, and reference staffing. Participating libraries staffed the service during weekdays and some evenings and weekends. At other times, LSSI staffed the service. During the six-month period (ending December 31, 2001) 369 chat reference sessions were logged involving persons self-identified as affiliated with Illinois State University. During the six-month period (ending December 31, 2002) 265 such sessions were logged, a 28 percent decrease from the same period in $2001 .^{23}$ In the fall of 2002, the Alliance Library System and the North Suburban Library System received funding from the Illinois State Library to jointly establish a chat reference service to replace two separate services offered by the systems. Called MyWebLibrarian, the new service operated through June 2004 much like Ready for Reference.

In the spring of 2004, Milner Library decided to leave the chat reference consortium to offer its own chat reference service. In planning its new chat service, Milner Library selected Docutek as its chat software provider. Access to the service was restricted to Illinois State University students, faculty, and staff. Service hours were limited to weekdays and early evenings, totaling thirty-six hours per week. Perhaps due in part to this limitation in service hours compared with the 24/7 service offered previously, the number of chat sessions during the six-month period (ending December 31, 2004) was only eighty-five. During the six-month period (ending December 31, 2005) 101 sessions were logged, still less than half the numbers logged in 2001 and 2002.

During these early experiences with chat reference, Milner librarians actively solicited feedback from patrons to determine whether the library should continue offering the service. Both the Ready for Reference and MyWebLibrarian services included a three-or-four-question survey that automatically appeared on the patron's computer at the end of the reference session. While positive, patron feedback was too brief to be very meaningful. Consequently, Milner librarians decided to conduct a lengthier survey. In late 2002, Milner librarians invited 135 chat reference patrons to complete an online survey consisting of eighteen questions, both open- and close-ended. Only fourteen patrons responded, far too few to provide clear direction. Still, the library implemented minor changes to the service such as 
redesigning the service Web site and expanding marketing efforts.

\section{METHODOLOGY}

In the summer of 2005, facing a decision whether to continue chat reference through Docutek, Milner librarians again sought input from library patrons. Having had limited success with popup and online surveys, we decided to try focus groups with the hope of obtaining deeper insights from patrons. Rather than target the few patrons who had used the service (as was the case with the previous two surveys) we decided to involve students regardless whether they had used the service or had even heard of it. While we were ultimately interested in discovering why students were not using our chat reference service, we decided to gather student feedback regarding chat reference within a broader context. We hoped to gain insights into our patrons' research habits, the ways they get help and would prefer to get help with their research, and the likelihood that chat reference would be one of those ways.

We developed a plan for a series of student focus groups, since the vast majority of our chat reference patrons were students rather than faculty or staff members. Suspecting that research habits and needs might vary significantly depending on student type, we divided our research into three phases defined by patron group: undergraduate students, graduate students receiving instruction on campus, and graduate students receiving instruction off-campus. We decided not to interview freshmen because we suspected they would not have sufficient college research experience to share.

In the first phase of our research, which is the basis of this article, we conducted seven focus groups with undergraduate students. We recruited students through instructors with whom we were familiar in our work as information literacy instructors or department liaisons. We did not have funds to offer inducements for participation in our groups, so we selected instructors willing to offer their students extra credit for taking part in the project. Instructors told students about the focus groups in class, directing interested students to register for sessions by e-mailing us. We accepted all volunteers.

Each of the seven focus groups had between five and ten participants. In all, forty-five students participated, or about three times the number of patrons participating in the 2002-03 online survey. We conducted the first focus group on August 8, 2005, and the last group on December
1, 2005. Sessions were conducted in the library and lasted approximately ninety minutes. With a goal of achieving consistency in questioning, we selected one member of the research team to moderate all seven sessions. The moderator used a ten-question guide (see appendix) to facilitate discussions. The other two librarians on the research team took notes, occasionally asking a participant to repeat or clarify a response for the record. We initially decided not to audio tape sessions because we thought the presence of recording equipment might stifle discussion. But, at the urging of our consultant, we began audio taping with the third session so we would have a record against which to check our notes.

We organized questions into three segments. We began with broad questions about how students conduct research, how and from whom they seek help with their research, if they use the library for their research, and if they use IM when conducting research. We then asked participants about their familiarity with and use of five specific reference services offered by Milner Library: desk reference, telephone reference, reference consultations, e-mail reference, and chat reference. We ended each discussion by asking participants how the library might best assist with their research and their likelihood of using any or all of the five Milner reference services, specifically chat reference. We adopted this general-to-specific approach in part to establish context for the later, more specific questions about chat. We were also concerned that some participants might respond positively to our questions about reference services thinking we expected and wanted such responses. We thought that by establishing a tone of comfort, openness, and honesty in the manner in which we handled the general questions, we might prevent skewed responses on the more specific questions that were the primary focus of our research. We benefited from this approach by receiving insights about research and library services that were richer than expected.

At the beginning of each session, we asked participants to identify their year in school and their major, suspecting that research strategies and reference needs might differ by discipline. During an early session, participants raised the issue of differences in library experience and training between students who started their college careers on campus (we will call them native students) and those who transferred from some other institution. Beginning with the third focus group, we asked participants to tell us whether they were native or transfer students. We contacted participants of earlier sessions via e-mail for this information. 
After each session, the two observers compiled a meeting record from their notes. After all seven sessions, we used the meeting records to create a master Excel spreadsheet of participant responses. Each entry in the spreadsheet represented one participant response and was coded with associated participant information. We sorted responses, looking for noteworthy differences based on year in school, major, or transfer status.

\section{RESULTS}

Of the forty-five focus group participants, twentytwo were seniors, twenty-one were juniors, and two were sophomores. Twenty-one were native students, twenty-four were transfer students. Fifteen participants were education majors, eleven were majoring in communication-related disciplines, seven were business majors, five were majoring in literature or language, and seven were majoring in other disciplines.

We have organized the following summary according to the three segments of questioning so the reader can follow the progression of responses and can study the responses by general theme. Because we did not utilize sampling methods to select our participants, the results are qualitative and not appropriate for quantitative analysis.

\section{How Students Conduct Research}

Most participants indicated they conduct their research at home rather than at the library. Some participants said they start their assignments at home and then come to the library to retrieve materials they need. About half of the participants mentioned starting their research on the Internet (using Google or Yahoo!, for example) and then continuing their research using the library catalog or article databases. Almost all participants indicated using the library either physically or virtually at some point in the research process. Many said they use the library Web site to identify appropriate resources and then come to the library to retrieve them. Several participants mentioned that some of their instructors want them to use library resources rather than Web sites. Many participants noted that they use library databases only when required by their instructors. Otherwise, they only use the Internet.

About half of the participants indicated they turn first to their instructors if they need help with their research. About half said they first seek help from the library. A few said they rely primarily on fellow students. Of those who said they seek help from their instructors, several said they did so because their instructors could clarify the assignment and might have specific resources to recommend. A few participants said some professors have loaned them personal copies of articles and books.

Participants were not shy about identifying problems encountered during the research process. About one-third of the participants expressed frustration with database searching, specifically with selecting an appropriate database, deciding what terms to search, getting too many or too few results, and locating article text. About one-quarter of the participants expressed frustration with not being able to find books or journals on the shelves where participants expected them to be. Several participants mentioned problems with library hours, either that the library should remain open longer or library hours should be more stable. Some said limited hours during the summer term are inconvenient, especially for students living off campus or out of town. Other problems noted by participants included finding appropriate places in the library to work in groups and difficulty getting adequate reference help at desks, especially during late evening and early morning hours when student workers are on duty.

To begin probing whether chat reference might be an appropriate reference medium, we asked participants to describe their use of IM when working on papers and speeches. The range of experience with IM varied from the participant who described herself as "an instant messaging junkie" to those who never use it. Most participants said they use IM at some time each day during the semester. Some said they use IM for course work, most frequently to communicate with group project members. One participant noted, "I actually have a [IM] section up for group members for the semester ... it has been helpful." She added that it was the first semester she had done so. Another said, "it's really been helpful for group projects." Many participants said they use IM for social contacts but not for research. It is common for them to have IM enabled while working on their projects and for them to stop their work to socialize with friends or family. One participant, said, "I'll be talking to my friends one minute [on IM] and writing my paper the next minute." Some participants described IM as a distraction and said they disable IM when trying to study. One participant explained, "I think the reason I come to the library and do my papers is to get away from instant messaging." Another said, "I shut down when I'm researching and writing." Several participants said they do not use IM at all, even for socializing. One participant said, 
"I'm computer illiterate. I don't even know how to use instant messaging to be honest."

During one session, most participants in the group said they rely on the library for its computers. Participants explained that their apartments do not have high-speed Internet access or that high-speed access is too expensive for them to use. These students instead come to the library to access the Internet and library databases, using either the computer lab or workstations scattered throughout the building.

\section{Use of Library Reference Services}

In general, participants did not know about reference services offered by the library. Desk reference service was the sole exception. Almost all participants said they knew they could ask for help at reference desks, and most participants said they had positive experiences doing so. About half of the participants were aware they could telephone the library for help. Several participants said it made sense that the library would offer telephone reference, but they had not thought much about it. One participant expressed surprise at the idea of telephone reference, saying "I'm shocked ... I've never heard a phone ring in the library" other than another patron's cell phone. Some participants were aware they could schedule a one-on-one consultation with a librarian, but most were not. Those who had consulted librarians were positive about the experience.

Most participants were not aware of e-mail or chat reference. Many participants knew e-mail reference exists or assumed it exists. Only a few participants had used it, but they described positive experiences with it. None of our participants had heard about chat reference. Hearing about chat reference for the first time, several participants said they associate the term "chat" with chat rooms rather than with one-on-one communication. They said they would not likely have tried the service if they had encountered the term "chat reference" because of negative associations with chat rooms.

Commenting on reference assistance in a more general sense, numerous participants said they were unsure what to expect from librarians. Some participants acknowledged not knowing that librarians are available to help them. For example, one participant said, "to be honest, I've never asked for help because I didn't figure it was part of your job description." Another said that she assumed "librarians organize the books and [makes shush sound] and that's it." Of those participants who expressed understanding of the service role of librarians, many expressed confusion about who among library staff is a librarian. One participant said she looks for older persons to approach. Several participants expressed reluctance to interrupt librarians to ask questions. One participant said she "assumed you guys [the librarians] are busy." Others stated that students would feel their questions are wanted if librarians would be more proactive in providing reference service. Specific suggestions included accompanying students to materials rather than pointing in their direction, making eye contact with students when they approach the reference desk, and occasionally leaving the desk to ask students if they need help.

\section{Reference Service Preferences}

Contrary to predictions in library literature about the ultimate demise of traditional reference services in favor of chat reference, our focus group participants expressed strong support for a range of reference services rather than any one service. But there was general agreement regarding preferred attributes of reference service. Most participants agreed that reference service should be convenient, immediate, personal, and high quality. Personalization seemed to be of particular importance, as evidenced by the following comments.

"Have a personal librarian."

"Go to the ... subject librarian."

"I like face-to-face if possible, but as a commuter student I prefer e-mail."

"I want to talk to a person. I don't like automated phone menus."

"Have a specific person to be able to e-mail."

"Ideally, face to face would be best."

"I like to communicate things with persons."

Somewhat paradoxically and particularly noteworthy, many participants said they prefer in-person reference, yet said they like to conduct their research at home. Participants also mentioned this desire for personalization in connection with remote reference services such as telephone, e-mail, and chat. More than one participant expressed reluctance to use e-mail or chat reference without knowing the person responding to them. Would the person be a librarian or a student? Would the person be affiliated with Milner Library or with some other institution? Although we did not mention 
the campus Web portal in our questioning, several participants mentioned it in their responses. They indicated their satisfaction with having a librarian assigned to them (typically, the librarian serving as liaison to their major department) and having contact information for their librarian displayed on their personalized Web portal home page.

Several participants talked about the quality of reference service, principally in connection with their desk reference experiences. Several participants said they received poor assistance from student workers at service points in the library, with some student workers demonstrating little desire to help and some lacking sufficient knowledge or skills. One participant said he has stopped going to the reference desk for help, because he knows more about research than student workers do. Related to the issue of immediacy, numerous participants said they would not e-mail the library for help because they did not want to wait for a response. Indeed, since IM and text messaging are immediate real time communication, several participants expressed a preference for using them in their daily lives rather than e-mail.

Because none of our participants had previously used chat reference, we provided participants information about the service at the end of each session, even demonstrating the service in some. Some participants were enthusiastic.

"I do feel like I've missed out."

"It's more instant than e-mailing and waiting for a response ... although I would like to talk to somebody in person ... I would feel less intrusive if I used the chat or e-mail."

"I do think the chat service is something that would be nice. But depending on the question and how much detail I need on it or ... maybe I would probably start with chat and, if I didn't feel I was completely satisfied, I would probably call in to get more detail."

"there's more than one option ... why not take the fastest one?"

"now that I know how it works ... it would be real helpful."

"if it is something I need . . . in an instant I would go and use that virtual chat or even call."

"I'd probably be more inclined to use that cyber thing with the librarian if you are just looking for ... general information."

"if you are just looking for ... general help, then it would be nice to just sit at your computer while you're looking around and say where can I find this ... what hints can you give me?"

"I would totally take advantage of it."

"pretty cool"

"I think the Internet thing is really important for commuters ... I probably would use that virtual thing often."

Some participants expressed reservations about the service. Several students questioned how it could help them with their college research. A few, presumably those who had never used IM, asked how it works or expressed concern that the service might be difficult to learn.

"I'd much rather just call ... instead of trying to figure out what to say and type it."

"I would think it was just like an e-mail."

"[it is not clear] where I would get the response."

"it's easier to talk to someone here [in the library]."

"you get more help if you are face to face with someone than if you have to type out a conversation."

"it's just tedious to have to type out big long conversations ... much rather be just

speaking with someone on the phone."

"IM is for BS not academics. It would involve a lot of typing ... not realistic."

"I don't have Internet at home anymore, so I can't use chat."

"I assumed that chat meant chat room. I would steer away from it ... there are crazy people out there."

"I don't like the idea of a chat room. I can't save what is sent."

"It depends on how easy the chat is, how quick it is to set up and access it."

"How long have you had this?"

"What would you need it for?"

"Like in a chat room?"

"Do you have to download something to use it?"

"I think I would do the chat if I knew how to do it." 


\section{Differences by Major or Native/ Transfer Status}

Using the Excel spreadsheet to sort participant responses, we analyzed comments by participant major and native/transfer status. We were particularly interested in knowing whether transfer students felt differently about research, IM, or reference, since more than half of our focus group participants were transfer students and about 40 percent of our study body is comprised of transfers. We did not find noteworthy differences in the range or frequency of responses between students in various majors or between native and transfer students. But several transfer students specifically mentioned feeling disadvantaged using the library compared with native students because they had not received formal library instruction at Milner Library. In one focus group, transfer students spent considerable time discussing the need for library training, although no clear direction emerged about how the library should provide such training and what it should cover.

\section{IMPLICATIONS FOR PRACTICE}

When considering the implications of our findings for future library services, we must remind ourselves that we interviewed a relatively small group of sophomores, juniors, and seniors in the humanities and social sciences. The fact that the responses from these groups were similar indicates to us that the views they expressed may be commonly held by the larger undergraduate community. But we know it is important to recognize inherent limitations of focus groups. Additionally, we suspect that we will hear different views expressed when we talk with graduate students. Despite these limitations, we are comfortable identifying some broad service implications.

We anticipated hearing that many of our students are unaware of our chat reference service. But we were not prepared for the numerous comments indicating that students are relatively unaware of the majority of our reference services. As noted previously, the only form of reference with which most students seemed familiar is desk reference. Even then, although students know they can ask questions at a reference desk, they seem unclear about the level of service they can expect. Several students seemed genuinely surprisedalthough very grateful- to hear that librarians really want to help them and are available for more than just quick questions. Clearly, one implication for us is that we need to address the way we promote all of our reference services. Marketing needs to be an ongoing effort because our student and faculty rosters are always changing. Marketing to our students should include outreach to our professors, since they are frequently contacted by our students for help and can, in turn, refer students to appropriate library services.

Transfer students in our groups seemed particularly unaware of services the library has to offer. They seemed to feel that they are at a disadvantage with respect to library research compared to native students. In retrospect, we probably should have anticipated this. We know we have a large number of transfer students, and we know we have no systematic way of reaching this group. The focus groups helped us realize that we need to make a concerted effort to reach this important segment of our population.

Although students mentioned having positive experiences with librarians, we were disappointed to hear several negative comments about library staff, particularly student workers. As noted previously, several participants mentioned looking for "older" people when they have a question in the library. Thus we may need to consider how we utilize, train, and supervise our student workers.

While many students indicated that they perform much of their research in their dormitory rooms or apartments, it was clear that many still value the library as a place. We expected to hear that students want everything online and that they do not want to have to come to the library. We certainly heard this attitude expressed, but we also heard how important the library is as a place for group meetings and study. One of the few complaints students had about librarians was that we do not enforce the quiet areas as diligently as students think we should. Several students also mentioned that they need the library for access to computers and printing. One student reminded us that we are not just dealing with the "rich kids" who own new computers and live in expensive apartments with high-speed Internet access. Since we hope to have a major building renovation in the future, the relative importance the students still put on the library as a physical place was worthy of note. We need to provide a welcoming and comfortable space where technology, group study areas, and quiet study areas are available, especially for students who do not have those amenities at home.

Nevertheless, the primary goal of our study was to better understand how our students conduct their research and whether they are likely to use chat reference. Again, we anticipated many of the participant responses, but some surprised us. We quickly discovered that even though we were 
primarily dealing with traditional-aged college students, not all of them fit the stereotype of the Millennial student. Many students in the focus groups use IM and seem comfortable with technology, but this was by no means universal. A few students even appeared to be somewhat Luddite in their attitudes. Although we still anticipate that each year's group of new students will be increasingly comfortable with technology, we cannot assume that all students have a high level of experience, comfort, or affinity with computers and other forms of electronic communication. This issue also emerged from a 2007 study of undergraduate students and information technology conducted by the EDUCAUSE Center for Applied Research. In this survey of more than 27,000 U.S. college students, more students commented on information technology barriers to learning than information technology enablers. Among the four primary barriers identified by respondents was the propensity of some instructors to overestimate student access to technology and comfort with it. ${ }^{24}$

Since several students mentioned not having access to computers in their apartments, we became keenly aware that some of our students either cannot afford to own computers or come from backgrounds where they have not had ready access to technology. We also became aware that many students do not have high-speed Internet access necessary for successful use of chat reference software like Docutek. Without high-speed access, students may be able to log into a chat reference session but will not be able to use advanced chat software features like co-browsing.

The reality that some of our students remain unable to cross the "digital divide" has implications for the planning of future reference services. Such students will be at a disadvantage if we move to offering our services only electronically. Therefore, we should strive to provide services that reach all of our students regardless of their age, economic background, preferred style of learning, and access to and comfort with technology. Additionally, we should offer training opportunities when new technologies such as chat reference are introduced rather than assume that patrons will know how to use the technology or can learn to use the technology on their own.

As we have mentioned, we discovered that use of the term "chat" in marketing virtual reference might be problematic. This issue first surfaced when we sought help with research design from Dr. Patrick O'Sullivan, a faculty member in our School of Communication. When we referred to virtual reference as "chat" in our early discussions with Dr. O'Sullivan, he looked somewhat per- plexed and asked, "you mean like a chat room?" His initial reaction was that most students, when hearing the term "chat," would think immediately of chat "rooms" and have negative reactions to the term.

Dr. O'Sullivan was right. Several participants expressed concern about asking a question in a chat room populated by persons they do not know. In retrospect, this misconception makes sense given the way commercial Internet services are organized and advertised. Yahoo!, for example, offers its Yahoo! Messenger service for customers wanting to talk online with an individual and a separate Yahoo! Chat service for customers wanting to talk with a group in a chat room. Once we explained our service, several participants asked how they would know who is responding to them when using the service and whether that person could be trusted to give credible information. We would like to attribute this response at least in part to the emphasis we place on information literacy. In terms of planning our reference services, we realize that if we continue offering chat reference in some form, we will be wise to market the service differently and more carefully choose our terminology.

Although some participants said they occasionally use IM when working on research, particularly to contact group project members, many said they associate IM with socializing rather than with academics. The comment by a participant that "IM is for BS not academics" seems to support Coffman and Arret's contention that "the general public has yet to accept chat as a means of communications for business deals and other more formal transactions." It also lends validity to their query that "if people have so far proved largely unwilling to embrace online chat for banking, insurance, retail, and other sales and customer service applications, what makes us so sure they will embrace it for reference?" ${ }^{25}$ Likewise, our feedback conforms to the Pew Study finding that, "in some situations, notably for more serious conversations, teens preferred face-to-face conversations." ${ }^{26}$ The preceding remark made by our participant leads us to question how much emphasis we should place on electronic reference relative to other reference services. Perhaps chat or IM will never emerge as a popular medium for reference services. Or perhaps it will just take time, as has been our experience with e-mail reference. In any case, it will help if we better explain to patrons the purposes for which chat reference is best suited, such as directional or policy questions that can be answered relatively quickly and with relatively few text characters. 
In his 2003 article on the future of reference, Joseph Janes observed that "libraries will need to provide a mix of services via a range of methods. . . Each [method] has its own particular strengths and weaknesses to specific user populations. Each of them will be more suitable for different kinds of questions and information needs. Each of them will likely play to the strengths of individual librarians. ${ }^{27}$ If our focus group participants are representative of the larger community of potential library users, Janes' predictions are correct. Students did not in general appear anxious to completely forego traditional forms of reference. For now, while reference is clearly in a time of transition, our focus group responses imply that the best approach will be to offer reference services in a variety of media. Students will then have options and use the services most appropriate to their current needs. Our services should include chat and IM but not at the exclusion of more traditional services such as desk and telephone reference. The question remains of how libraries will staff both in-person and virtual reference services given the economic realities in an era of shrinking budgets.

A recent trend in reference service seems to be a move from use of chat reference software to use of IM. Judging from the puzzled looks and questions from our participants when we demonstrated our chat reference service, even among IM users in the groups, maybe adopting IM would be preferable. Perhaps virtual reference usage would increase if we adopt technology already familiar to our students.

When we asked students to describe their ideal form of reference, it was striking to us how many times we heard the word "personal." Admittedly, some students like the relative impersonal and anonymous nature of electronic reference, but the recurring preference for personal service was noteworthy. Several students said that their "ideal" form of reference would be a "personal" librarian. Some students also mentioned liking "face-to-face" communication and talking to "real" persons. Other students mentioned that they like contacting librarians assigned to their departments whether by telephone, e-mail, or in person. We also found that many students tend to go to their professors for help first. Certainly, many students view their professors as authorities on their topics and the persons whom they have to please. Moreover, perhaps it is also significant that this contact with a professor is a "personal" encounter. Students said they frequently ask a friend for helpagain a "personal" encounter. We were struck by how many students mentioned returning to their public and community college libraries-where they know their way around and perhaps where they find the environment more comfortable and "personal." Our findings support James Rettig's assertion that "high-tech and high touch are equally important." ${ }^{28}$ They are also consistent with Southwick's finding that digital reference users prefer to send questions to librarians they already know rather than to a generic library account. ${ }^{29}$

Emphasizing the personal touch may be key if our patrons are to feel comfortable asking questions regardless whether at a desk or by telephone, e-mail, or IM. What might this mean specifically? In the case of traditional desk reference, we must take care to be approachable, offer patrons our full attention while with them, offer to accompany patrons to shelf locations rather than simply point to them, and occasionally approach patrons rather than wait for patrons to approach us. In the case of telephone reference, we should avoid automated answering systems and remember to offer our name and position at the outset of a conversation. In the case of chat reference or IM, we would do well to emphasize in marketing the service that only librarians affiliated with the sponsoring library answer questions, and then only one-onone rather than in a group setting. If using IM, we could make patrons more comfortable by using personal screen names instead of anonymoussounding names like "Milner librarian."

The desire for personal connections suggests rethinking the traditional chat reference model of set service hours staffed by a pool of librarians. Perhaps we could more effectively reach our patrons through a decentralized IM service by establishing and advertising personal IM accounts and encouraging students to IM the librarian assigned to serve their department. We could advertise our IM screen names and availability on the library Web site and on the library channel of our campus Web portal.

We also think that our study may have implications for others conducting library research. From our review of library literature, it seems that academic librarians seldom use focus groups to solicit feedback from their patrons. Most research we reviewed instead utilized e-mail and online surveys, especially pop-up surveys. This is unfortunate. We have learned more about our patrons' perceptions and needs by talking directly to them in these focus groups than we had previously learned through surveys. In addition, most research on perceptions of library service relies on views of library users instead of both users and nonusers. While this limitation is understandable because of the difficulty reaching nonusers, it too is unfortunate. Because very few of our partici- 
pants had used our reference services, we received valuable feedback to help us design reference services that address unmet needs and increase our presence on campus.

Had we conducted this depth of research when planning our chat reference service, indeed all of our reference services, we might have saved substantial investments of both time and money in a service that so far has had disappointingly low usage. With the feedback we now have, we are better equipped to offer services that are popular with our undergraduate students and, more importantly, meet their research needs. In coming months we hope to expand our focus group discussions to other segments of our academic community and to develop a systematic effort to communicate regularly with our community in this manner.

Since conducting our research, our library has dropped its use of chat reference software in favor of IM. This was done in an attempt to increase our digital reference usage while saving money (approximately $\$ 2,000$ per year in hosting fees). Late in the summer of 2006, in anticipation of our 2006-07 academic year, our library initiated an IM reference service to replace chat reference. The service utilizes AOL Instant Messenger. During the six-month period (ending December 31, 2006) 264 IM reference transactions were logged by our staff. This represents a 161 percent increase over the same period in 2005 . How satisfied these patrons are with the new service and whether they intend to keep using it are questions that remain to be answered. These are important questions for a future assessment project.

Acknowledgements: The authors thank Dr. Patrick O'Sullivan, formerly of the Illinois State University School of Communication and currently director of the Illinois State University Center for Teaching, Learning, and Technology, for his assistance with research design.

\section{References}

1. Steve Coffman and Susan McGlamery, "The Librarian and Mr. Jeeves," American Libraries 31, no. 5 (May 2000): 66-69.

2. Steve Coffman and Linda Arret, "To Chat or Not to Chat-Taking Yet Another Look at Virtual Reference, Part 2," Searcher: The Magazine for Database Professionals (Sept. 2004), www.infotoday.com/searcher/sep04/ arret_coffman.shtml (accessed June 13, 2006).

3. Kelly M.Broughton, "Usage and User Analysis of a Real-Time Digital Reference Service," Reference Librarian no. 79/80 (2002/2003): 183-200; Marianne Foley, "Instant Messaging Reference in an Academic Library: A Case Study," College \& Research Libraries
63, no. 1 (Jan. 2002): 36-45; Jo Kibbee, David Ward, and Ma Wei, "Virtual Service, Real Data: Results of a Pilot Study," Reference Services Review 30, no. 1 (2002): 25-36; Margie Ruppel and Jody Condit Fagan, "Instant Messaging Reference: Users' Evaluation of Library Chat," Reference Services Review 30, no. 3 (2002): 183-97; Bruce Stoffel and Toni Tucker, "E-mail and Chat Reference: Assessing Patron Satisfaction," Reference Services Review 32, no. 2 (2004): 120-40.

4. Alison M Bobal, Cynthia M. Schmidt, and Roxanne Cox, "One Library's Experience with Live, Virtual Reference," Journal of the Medical Library Association 93, no. 1 (Jan. 2005): 123-25.

5. Lisa R. Horowitz, Patricia A. Flanagan, and Deborah L. Helman, "The Viability of Live Online Reference: An Assessment," portal: Libraries and the Academy 5, no. 2 (Apr. 2005): 239-58.

6. Janice T. Koyama, "http://digiref.scenarios.issues," Reference \& User Services Quarterly 38, no.

1 (1998): 51-53.

7. Myoung C. Wilson, "Evolution or Entropy?: Changing Reference/User Culture and the Future of Reference Librarians," Reference \& User Services Quarterly 39, no. 4 (Summer 2000): 387-90.

8. Horowitz, Flanagan, and Helman, "The Viability of Live Online Reference: An Assessment," 254, 246.

9. Corey M. Johnson, "Online Chat Reference: Survey Results from Affiliates of Two Universities," Reference E User Services Quarterly 43, no. 3 (Spring 2004): 242.

10. OCLC White Paper on the Information Habits of College Students: How Academic Librarians Can Influence Students' Web-Based Information Choices," www.oclc.org/research/announcements/2002-06-24. htm (accessed Mar. 16, 2006).

11. Broughton, "Usage and User Analysis of a Real-Time Digital reference Service," 195.

12. David Ward, "Why Users Choose Chat: A Survey of Behavior and Motivations," Internet Reference Services Quarterly 10, no. 1 (2005): 29-46.

13. Foley, "Instant Messaging Reference in an Academic Library: A Case Study," 44; Ruppel and Fagin, "Instant Messaging Reference: Users' Evaluation of Library Chat," 190; Ward, "Why Users Choose Chat: A Survey of Behavior and Motivations," 36.

14. Ian J. Lee, "Do Virtual Reference Librarians Dream of Digital Reference Questions?: A Qualitative and Quantitative Analysis of Email and Chat Reference," Australian Academic \& Research Libraries 35, no. 2 (June 2004): 105.

15. Kibbee, Ward, and Wei, "Virtual Service, Real Data: Results of a Pilot Study," 33.

16. Jonathan D. Lauer and Steve McKinzie, "Bad Moon Rising: A Candid Examination of Digital Reference and What It Means to the Profession," The Reference Librarian no. 79/80 (2002-03): 45-56.

17. Horowitz, Flanagan, and Helman, "The Viability of Live Online Reference: An Assessment," 256.

18. Coffman and Arret, "To Chat or Not to Chat-Taking Yet Another Look at Virtual Reference, Part 2."

19. Lee, "Do Virtual Reference Librarians Dream of Digital Reference Questions?: A Qualitative and Quantitative Analysis of Email and Chat Reference," 106.

20. Amanda Lenhart, Mary Madden, and Paul Hitlin, "Teens and Technology: Youth are Leading the Transition to a Fully Wired and Mobile Nation," www 
.pewinternet.org/pdfs/PIP_Teens_Tech_July2005web .pdf (accessed May 23, 2006).

21. Carol Tenopir, "Rethinking Virtual Reference," Library Journal 129, no. 18 (Nov. 1, 2004): 34.

22. Richard A. Krueger and Mary Ann Case, Focus Groups: A Practical Guide for Applied Research (Thousand Oaks, Calif:: Sage, 2000); Marilyn Von Seggern and Nancy J. Young, "The Focus Group Method in Libraries: Issues Relating to Process and Data Analysis," Reference Services Review 31, no. 3 (2003): 272-84; Graham R. Walden, "Focus Group Interviewing in the Library Literature: A Selective Annotated Bibliography 1996-2005," Reference Services Review 34, no. 2 (2006): 222-41.

23. Stoffel and Tucker, "E-mail and Chat Reference: Assessing Patron Satisfaction," 122.

24. Gail Salaway et al., The ECAR Study of Undergraduate
Students and Information Technology, 2007 (Boulder, CO: EDUCAUSE Center for Applied Research, 2007), 86.

25. Coffman and Arret, "To Chat or Not to Chat-Taking Yet Another Look at Virtual Reference, Part 2."

26. Lenhart, Madden, and Hitlin, "Teens and Technology: Youth are Leading the Transition to a Fully Wired and Mobile Nation," 31.

27. Joseph Janes, "What Is Reference For?" Reference Services Review 31, no. 1 (2003): 23.

28. James Rettig, "Technology, Cluelessness, Anthropology, and the Memex: The Future of Academic Reference Service," Reference Services Review 31, no. 1 (2003): 17.

29. Silvia Barcellos Southwick, "Understanding Intermediation in a Digital Environment: An Exploratory Case Study" (Ph.D. diss., Syracuse Univ., 2001), 231.

\section{APPENDIX: FOCUS GROUP DISCUSSION QUESTIONS}

The purpose of this focus group is to help us determine how you go about looking for information for your course work so we can design our library services to best meet your needs.

We'd like to start by getting to know a little more about each of you. Let's go around the table and have each of you introduce yourself.

1. Tell us your first name, year in school, major, and where you are when you conduct most of your research . . . at home, at work, in the library, or someplace else.

2. How do you look for information when writing papers or speeches? Do you search Google, search library databases, ask for help from other people, or do something else?

3. When looking for information for your papers and speeches, what types of problems do you run into?

4. Where do you go for help when you have a question about finding information for your papers and speeches?

5. Do you ever use Instant Messaging when you are working on your papers and speeches?

6. Do you use Milner Library or the library Web site when you are writing your papers and speeches? If so, how?

7. Can you tell us if you are aware that the following services exist and describe any experiences you have had using them?

- In-person reference at the library

- Phone reference

- Consultations

- E-mail

- Chat.

8. What would be your ideal way to get help in finding information for your papers and speeches?

9. What would be your ideal way to get help using Milner Library?

10. Based on what you have learned in this session, how likely are you to use reference services available through Milner Library ... desk reference, phone, consultations, e-mail, chat?

11. Is there anything else you'd like to tell us? 